\title{
Implications of the Revisions and Revaluation of Office/ Outpatient Evaluation and Management Codes for Neuroradiology Reimbursement
}

\author{
(D) K.Y. Wang, (D).A. Hirsch, (D) G.N. Nicola, (D) L.P. Golding, (D) R.K. Lee, and (D) M.M. Chen
}

\begin{abstract}
SUMMARY: In the 2020 Final Rule, the Center for Medicare \& Medicaid Services adopted a new coding structure and accepted the substantial increase in valuation for office/outpatient Evaluation and Management codes set to begin in 2021. Given budget neutrality requirements, the projected increase in reimbursement will require a reduction in the conversion factor to offset such increases. The aim is to inform neuroradiologists the impact of these proposed changes on reimbursement and the profession.
\end{abstract}

ABBREVIATIONS: AMA = American Medical Association; ACR = American College of Radiology; CF = conversion factor; CMS = Centers for Medicare \& Medicaid Services; COVID-19 = coronavirus disease 2019; CPT = Current Procedural Terminology; $\mathrm{E} / \mathrm{M}=$ evaluation and management; $\mathrm{MDM}=$ medical decision-making; MedPAC = Medicare Payment Advisory Commission; MPFS = Medicare Physician Fee Schedule; RUC = AMA/Specialty Society Relative Value Scale Update Committee; RVU = relative value unit

O n November 1, 2019, the Centers for Medicare \& Medicaid Services (CMS) finalized major revisions to the office/outpatient evaluation and management (E/M) Current Procedural Terminology (CPT) codes. These changes at first glance may not seem to impact diagnostic neuroradiology because radiologists typically do not bill office/outpatient E/M codes. However, on closer inspection, there are worrisome ramifications. The purpose of this article is to review these changes and discuss their impact on the profession. It is necessary to first understand Medicare reimbursement and how furnished services translate into fee schedule payments, to appreciate these implications.

To ensure an accurate determination in reimbursement, the American Medical Association (AMA) created the CPT system in 1965 to uniformly describe medical services and procedures. ${ }^{1}$ Each service furnished is given a unique and billable CPT code, of which there are currently more than 10,000. Since 1992, the

Received March 17, 2020; accepted after revision April 21.

From the Department of Radiology (K.Y.W.), Baylor College of Medicine, Houston, Texas; Department of Radiology (J.A.H.), Massachusetts General Hospital, Boston, Massachusetts; Hackensack Radiology Group (G.N.N.), River Edge, New Jersey; Triad Radiology Associates (L.P.G.), Winston Salem, North Carolina; Department of Radiology (R.K.L.), Einstein Healthcare Network, Sydney Kimmel College at Thomas Jefferson University, Philadelphia, Pennsylvania; and Department of

Neuroradiology (M.M.C.), Division of Diagnostic Imaging, University of Texas MD Anderson Cancer Center, Houston, Texas.

Please address correspondence to Kevin Yuqi Wang, MD, Baylor College of Medicine, Department of Radiology, BCM-310, One Baylor Plaza, Houston, TX 77030; e-mail: yuqiw@bcm.edu; @MelissaChenMD

\footnotetext{
- Indicates open access to non-subscribers at www.ajnr.org

Indicates article with supplemental on-line tables.

Indicates article with supplemental on-line photo.

http://dx.doi.org/10.3174/ajnr.A6619
}

compensation system for physician services by the CMS is based on a resource-based relative value scale as published in the Medicare Physician Fee Schedule (MPFS). Medicare payments reflect the actual resources used in furnishing specific services as well as preserving relativity among other services. ${ }^{1}$ The relative compensation for furnishing a service is determined by assigning a relative value unit (RVU) and is dictated by 3 components: physician work (professional component), practice expense (technical component), and professional liability insurance. Physicians play an integral role in providing input toward the valuation of new and revised CPT codes. Through the AMA/Specialty Society Relative Value Scale Update Committee (RUC) and its robust survey of $>50$ specialty societies, valuations for CPT codes are determined. The RUC then recommends these valuations for the MPFS to the CMS, with acceptance rates that were historically $>90 \%{ }^{2}$

Subsequently, the conversion factor (CF), which is determined by the CMS and can be viewed as a dollar amount multiplier, ultimately "converts" the work of the RVU to a dollar amount after a geographic cost adjustment. Most important, the calculation for the CF is revisited annually and is budget-neutral. In other words, any increase in relative expenditures in one area of physician services would need to be offset by decreases in other areas to maintain budget neutrality. With only minor annual adjustments, the CF has been relatively flat since its inception, ranging from $\$ 35.7547$ (2015) to $\$ 36.0896$ (2020). In contrast, the non-seasonally adjusted inflation rate for medical care during that same period was $11.6 \%{ }^{3}$ However, with upcoming changes in 2021 to the new coding structure and valuation of the office/outpatient $\mathrm{E} / \mathrm{M}$ CPT codes, ${ }^{2}$ the CF for 2021 is almost certainty expected to be 
revised downward to maintain budget neutrality with major implications for neuroradiologists.

\section{HISTORICAL PERSPECTIVE OF OFFICE/OUTPATIENT E/M CODES}

The office/outpatient E/M codes are a category of CPT codes frequently billed by physicians who see patients in the office, ambulatory, or outpatient setting. E/M codes, in general, are the most frequently billed CPT codes, and specifically, office/outpatient E/M codes account for approximately $20 \%$ of all Medicare spending. ${ }^{1}$ To bill one of these codes, the services furnished must meet certain documentation requirements based on the definition of the code. However, physicians have been increasingly vocal about $\mathrm{E} / \mathrm{M}$ documentation requirements being administratively burdensome and redundant, resulting in unnecessary documentation irrelevant to the patient's care, not accurately capturing the most clinically meaningful level of care, and increasing the number and cost of audits.

The typical radiologist, particularly those focused on diagnostic imaging, may not be familiar with office/outpatient E/M codes. While $\mathrm{E} / \mathrm{M}$ visits are provided by nearly all medical specialties, they represent a disproportionate component for those in primary care and certain office-based specialty settings. ${ }^{1}$ For the reader to appreciate the extent of the granularity and burden in documentation and to better understand the rationale and implications for the upcoming changes, the current $\mathrm{E} / \mathrm{M}$ visit documentation structure will be briefly discussed (On-line Figure). First, billing Medicare for an E/M visit requires the selection of the CPT code that accurately represents the level of E/M service furnished, of which there are 5 (eg, CPT codes 99201-99205 for new patients and CPT codes 99211-99225 for established patients). Unlike in imaging in which the complexity of patients is not captured by CPT codes, $\mathrm{E} / \mathrm{M}$ codes capture different levels of complexity in patients based on the level of $\mathrm{E} / \mathrm{M}$ services billed. ${ }^{4}$ In general, the higher the complexity of the visit, the higher the level of E/M service and reimbursement for the CPT code. Three key components are mainly considered in determining the level of E/M service: history, physical examination, and medical decision-making (MDM). MDM documentation is the most challenging, and higher level codes in general require more extensive documentation. However, if a visit constitutes $>50 \%$ of counseling or coordination of care, then only the time spent during the visit is used to determine the level of E/M service.

\section{IMPETUS FOR CHANGE BY THE CMS}

In the backdrop of the "Patients Over Paperwork" initiative of the CMS launched in 2017 to reduce regulatory burdens, the increasingly outdated documentation requirements for $\mathrm{E} / \mathrm{M}$ codes led the CMS to propose major changes to the coding, documentation, and payment structure of $\mathrm{E} / \mathrm{M}$ visits when it released the 2019 MPFS proposed rule in July 2018. After considerable input from stakeholders, the finalized changes to $\mathrm{E} / \mathrm{M}$ visits were released in the 2019 MPFS Final Rule in November 2018. They were slightly different from those in the 2019 MPFS proposed rule, and most were intended to take effect on January 1, 2021 (On-line Table 1). These changes specifically included consolidating levels 2-4 E/M services to a single (also referred to as blended) rate of payment based on a weighted average of historical use obtained from the claims data. As a result, physicians who take care of patients with complex conditions who do not meet the requirements for a level $5 \mathrm{E} / \mathrm{M}$ visit would be compensated at the same rate as a level $2 \mathrm{E} / \mathrm{M}$ visit. Moreover, rather than using all 3 key components, the 2019 MPFS Final Rule allowed the option of satisfying documentation using either only MDM or time (regardless of whether $>50 \%$ of the time was spent counseling or coordinating care). This option allowed physicians to document only factors that are most important in taking care of patients rather than the burdensome requirements under the current guidelines. Last, 3 new "extended visit" add-on G codes were adopted to report additional resource costs that were still not appropriately reflected in the revised outpatient $\mathrm{E} / \mathrm{M}$ code set (GPRO1, GPC1X, and GCG0X). ${ }^{1}$

\section{RESPONSE BY ORGANIZED MEDICINE}

Many specialty societies, including the American College of Radiology (ACR) and AMA, raised concern over the 2019 MPFS Final Rule, particularly the collapse of the payment of 2-4 levels of E/M services. In direct response to the changes by the CMS, the AMA established the Joint AMA CPT Workgroup on E/M represented by a wide array of specialties, stakeholders, and members of the CPT Editorial Panel and RUC to develop an alternative solution and derive their own set of consensus recommendations. ${ }^{1}$ The Workgroup presented their recommendations to the Panel in February 2019 and the recommendations were aligned with the initiatives already established by the CMS. They were similarly intended to take effect on January 1,2021, and also included the option of using either only MDM or time (On-line Table 1). Instead of consolidating them, the CPT Editorial Panel retained the 5 levels of E/M services for established patients (CPT codes 99211-99215) and modified new patient visits to 4 levels of E/M services by deleting CPT code 99201 (previously defined as a level $1 \mathrm{E} / \mathrm{M}$ visit for a new patient). The rationale was because level 1 and $2 \mathrm{E} / \mathrm{M}$ visits for new patients are currently differentiated by the 2 soon-to-be-defunct key components (history and physical examination). They also proposed the add-on CPT code (99XXX) for prolonged visits that would only be used when time (rather than MDM) is chosen to determine the level of E/M service. Additional changes included code descriptor revisions and modifications to the MDM and time-interpretive guidance. The AMA reports that its approach better reduces documentation burden, more accurately reflects the current practice of medicine, is more clinically intuitive, and is more likely to be adopted by third party payers than policies within the 2019 MPFS Final Rule. ${ }^{1}$ The revised E/M codes were subsequently resurveyed and then revalued at the RUC meeting in April 2019, with the Committee's final recommendations ultimately being submitted to the CMS.

\section{ADOPTION OF THE 2020 MPFS PROPOSED AND FINAL RULE}

The CMS largely adopted the alternative proposals set forth by the CPT Editorial Panel in the 2020 MPFS proposed rule of August 2019 (On-line Table 1). ${ }^{1}$ Specifically, the CMS adopted the Panel's 


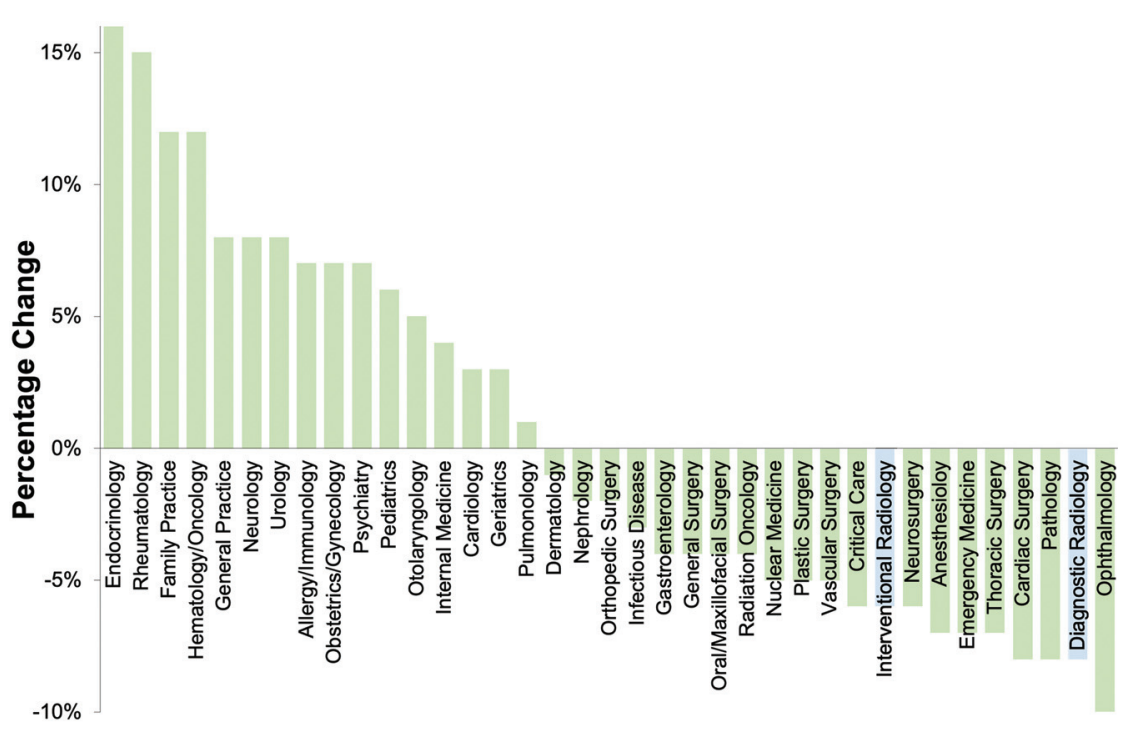

FIGURE. This histogram depicts the estimated percentage change in combined payment (encompassing work, practice expense, and malpractice RVUs) at the specialty level for the complete 2020 calendar year had the changes to the office/outpatient E/M visit coding and valuation hypothetically been in effect starting January 1, 2020 (rather than January 1, 2021). The blue bars highlight the $6 \%$ and $8 \%$ payment decreases projected for interventional and diagnostic radiology, respectively. This impact analysis was performed by the CMS, considered for illustrative purposes only, and adapted and modified from Table 120 of the 2020 MPFS Final Rule. ${ }^{2}$

Preliminary data from the RAND Corporation suggest that these global surgery codes may have been misvalued. For example, only $4 \%$ and $39 \%$ of the expected postoperative visits were reported for procedures with 10- and 90-day global periods, respectively. ${ }^{6}$ Because of uncertainty regarding the number of appropriate postoperative $\mathrm{E} / \mathrm{M}$ visits included as well as specifically how postoperative visits should be valued in global codes relative to stand-alone E/M visits, the CMS, at this time, did not adopt the RUC-recommended changes to these global surgery codes in the 2020 MPFS Final Rule. The rationale was that adopting the recommended revised values for $\mathrm{E} /$ $\mathrm{M}$ services to the global surgery codes would exacerbate any potential existing relativity issues and further contribute to potential misvaluation. ${ }^{2}$

\section{IMPLICATIONS FOR NEURORADIOLOGY}

interpretive guidance framework and coding language. CPT code 99201 was removed, and the remaining 4 established and 5 new patient levels of E/M services were preserved. The CMS accepted the RUC recommendations on the valuation of retained levels of $\mathrm{E} / \mathrm{M}$ services rather than the previously proposed blended rate. In addition, the CMS adopted the new prolonged-visit CPT add-on code (99XXX). The 99XXX CPT add-on code may be used only with level $5 \mathrm{E} / \mathrm{M}$ visits and may be billed multiple times for the same encounter for every 15-minute increment of additional time required. In addition, because the CMS believed that the revalued $\mathrm{E} / \mathrm{M}$ codes still do not accurately capture resource costs for certain types of $\mathrm{E} / \mathrm{M}$ visits (eg, ongoing care during primary care and certain specialist visits related to a complex chronic condition), the add-on G code GPC1X initially proposed in the 2019 MPFS proposed rule will be retained. The update in valuation is scheduled to take effect on January 1, 2021. Work RVUs will increase by up to $46 \%$ depending on the E/M code, and the add-on GPC1X code was valued via a crosswalk to $100 \%$ of another CPT code valued at 0.33 work RVUs (On-line Table 2). ${ }^{1,2}$

\section{GLOBAL SURGERY CODES}

In addition to the above recommendations, there were also RUC recommendations to adjust valuations for the E/M component of codes, with a global period to ensure relativity with the changes made to E/M visits. ${ }^{1}$ Codes with a global period are often used by physicians billing for surgical procedures, and these global surgery codes previously existed with either a 10- or 90-day global period in which a certain number of postoperative $\mathrm{E} / \mathrm{M}$ visits are assumed to be furnished and included in their valuation during that period. However, there are major challenges in accurately accounting for the number of expected postoperative visits typically furnished and the consequent accuracy of the valuation. ${ }^{5}$
Why are these changes important to neuroradiology? At first glance, they may seem less relevant to specialties that do not routinely furnish office visits, though interventional radiologists do bill for E/M visits. More important however, the secondary effects and redistribution of payments as a result of the increased valuation of $\mathrm{E} / \mathrm{M}$ visits are substantial. As mentioned above, the CMS is required by law to annually adjust the $\mathrm{CF}$ to maintain budget neutrality if changes in RVUs result in an increase or decrease in the overall fee schedule. Specifically, changes in RVUs may not result in annual Medicare expenditures differing by $>\$ 20$ million from what expenditures would have been without such changes. The office/outpatient E/M codes account for one of the largest portions of all Medicare spending, approximately 27\% of allowed charges in 2017, ${ }^{7}$ and even a small increase in valuation of $\mathrm{E} / \mathrm{M}$ codes will result in a sizeable increase in overall Medicare spending if unadjusted. Given the statutory requirement for budget neutrality, the projected increases in $\mathrm{E} / \mathrm{M}$ visit reimbursement will require a substantial reduction in the CF to offset such increases. Consequently, all services furnished will see decreases in payments due to the reduction in the CF. However, the increased valuation of E/M services will offset these decreases and may even increase overall payments for specialties that frequently bill for these services, whereas specialties that do not would see overall payment decreases.

In the 2020 MPFS proposed and Final Rule, the CMS published an estimated impact table at the specialty level regarding implementing changes to the $\mathrm{E} / \mathrm{M}$ visits had they hypothetically been effective this year (Figure). ${ }^{1,2}$ By specialty, diagnostic radiology would experience one of the largest reductions in payments, approximately $8 \%$, and interventional radiology would also see a substantial decrease, albeit to a lesser degree. ${ }^{1,2}$ The impact on neurointerventionalists is lessened because many have their own 
clinics and bill E/M codes. The analysis does assume 100\% use of the GPC1X add-on code by several specialties, though the CMS reports that the analysis is only for illustrative purposes. If the increased valuation of the $\mathrm{E} / \mathrm{M}$ visits is further applied to global surgery codes, this step will likely trigger an additional reduction in the CF. To ensure relativity among other E/M services, a potential subsequent revaluation of other $\mathrm{E} / \mathrm{M}$ codes including inpatient and nursing facility care services may further reduce the $\mathrm{CF}$ and result in further payment reductions for diagnostic and interventional radiology. Moreover, with the coronavirus disease 2019 (COVID-19) pandemic, expansion of telehealth services, including $\mathrm{E} / \mathrm{M}$ codes, and payment parity by the CMS could impact the MPFS, particularly if relaxation of regulations continues after the pandemic.

Assuming a scenario under the 2020 MPFS Final Rule Impact Table, ${ }^{2}$ a diagnostic neuroradiologist receiving $\$ 400,000$ annually from professional fees alone from managing a population comprising 30\%-50\% Medicare patients could see a payment decrease by $\$ 6000-\$ 10,000$ per year, with further impact depending on how private payers adjust reimbursements.

The changes proposed by the CMS will take effect on January 1,2021 , with the redistribution of payments from specialists to primary care physicians having been long advocated by the Medicare Payment Advisory Commission (MedPAC), a nonpartisan agency that provides analysis and advice on Medicare to Congress. The MedPAC has been concerned that the undervaluing of $\mathrm{E} / \mathrm{M}$ services may lead to beneficiary access issues and influence the pipeline of physicians in primary care specialties. Similar concerns regarding access of Medicare beneficiaries to advanced imaging services as a result of the $2021 \mathrm{E} / \mathrm{M}$ policy change have been raised by the ACR.

\section{MITIGATION AND OPPORTUNITIES}

Updating documentation and payment for primary care physicians to ensure adequate access for beneficiaries is important. However, to accomplish this with redistribution of reimbursement away from specialists could lead to access issues in other areas. Although reimbursement changes specifically apply to Medicare patients, there will likely be downstream effects to private payer contracts that are typically negotiated as a percentage of Medicare payments. The combination of payment decreases from both Medicare and private payers may result in a diminution of neuroradiology professional and technical fees.

Congress and the CMS could thoroughly study the impact of these revised E/M codes and assess unexpected shifts in claims to higher patient-complexity E/M codes. It is important that this analysis be performed before revising and revaluing any other $\mathrm{E} / \mathrm{M}$ codes, such as those related to inpatient and nursing facility care. The CMS could evaluate the cost-sharing implications of these higher paying E/M services to the patient, who is required to pay a $20 \%$ copay of this higher valuation. This increased cost that is passed on to the patient may actually decrease access to primary care. ${ }^{8}$ The ACR and ASNR have already urged Congress to consider temporarily suspending the budget-neutrality option by which the CMS is statutorily required to abide, ${ }^{7}$ and this request was again reiterated by the ACR and the ASNR for the finalized implementation of the COVID-19 Phase 4 Relief
Package. Other options to mitigate the impact in the payment redistribution are to encourage a dampening policy so that reductions are phased in over multiple years or to implement a ceiling and floor in terms of maximum annual decreases and increases in payments at the specialty levels.

A potential mechanism to dampen the 2021 proposed changes includes the elimination of the add-on G code GPC1X. The add-on code alone will substantially exacerbate the payment redistribution already present in the $\mathrm{E} / \mathrm{M}$ code changes. Multiple organizations, including MedPAC, have called into question the need for this particular code as well as the lack of guidance by the CMS in determining the necessity of billing for this code. The changes to the office/outpatient E/M code family, as well as other recent additions of CPT codes for chronic care management and complex chronic care management (CPT codes 99487, 99489-99490) and for care transition (CPT codes 99495-99496), signal that patient-facing and care coordination activities are most valued. As payment policy evolves, neuroradiologists should consider what opportunities are available within this new paradigm.

Neuroradiologists who perform spine procedures can consider taking a more active role in the longitudinal care of patients by expanding their practice to include a clinic that bills E/M services. ${ }^{9}$ Advanced midlevel providers, such as nurse practitioners or physician assistants, could help coordinate the clinic, provide patient education, and follow-up with patients after the procedure.

Ultimately, these E/M changes are only relevant in a fee-forservice environment, and there are known efforts to move toward value-based payment models. With these come another impetus for radiologists to seek novel ways to offset decreases in fee-forservice payments with data-driven efforts to deliver and demonstrate value. Neuroradiologists will need to take a more active role in defining unique practice paradigms outside the traditional fee-for-service in which radiologists may have patient-facing activities. Currently, there may be limited opportunities for neuroradiologists to bill for these types of services, but the impetus to focus on face-to-face interactions and care coordination activities has never been stronger.

Disclosures: Joshua A. Hirsch—UNRELATED: Consultancy: Medtronic, Relievant Medsystems, InNeuroCo, Comments: Medtronic, consultant; Relievant Medsystems, Data Monitoring Committee member; InNeuroCo, consultant; Grants/Grants Pending: Harvey L. Neiman Health Policy Institute. Greg N. Nicola—UNRELATED: Board Membership: Hackensack Meridian Health Partners*; Consultancy: Guidepoint; Stock/Stock Options: Neutigers. *Money paid to the institution.

\section{REFERENCES}

1. Center for Medicare \& Medicaid Services. 2020 Medicare Physician Fee Schedule Proposed Rule. Federal Register 2019;84:40482-1289

2. Center for Medicare \& Medicaid Services. 2020 Medicare Physician Fee Schedule Final Rule. Federal Register 2019;84:62568-3563

3. Bureau of Labor Statistics. Consumer Price Index. Latest Numbers. 2020. https://www.bls.gov/cpi/latest-numbers.htm. Accessed January 19, 2020

4. Chen MM, Hirsch JA, Lee RK, et al. Determining the patient complexity of head CT examinations: implications for proper valuation of a critical imaging service. Curr Probl Diagn Radiol 2020;49:177-81 CrossRef Medline

5. Mulcahy AW, Merrell K, Mehrotra A. Payment for services rendered: updating Medicare's valuation of procedures. N Engl J Med 2020; 382:303-06 CrossRef Medline

AJNR Am J Neuroradiol 41:1160-64 Jul 2020 www.ajnr.org 
6. Kranz AM, Ruder T, Mehrotra A, et al. Claims-Based Reporting of Post-Operative Visits for Procedures with 10- or 90-Day Global Periods. RAND Corporation. Research Reports. 2019. https://www. rand.org/pubs/research_reports/RR2846.html. Accessed February 17, 2020

7. American College of Radiology. ACR Urges Congress to Suspend Budget Neutrality for E/M Changes in CY 2020 MPFS Proposed Rule. October 1, 2019. News Releases Web site. https://www.acr.
org/Media-Center/ACR-News-Releases/2019/ACR-Urges-CMS-toSuspend-Budget-Neutrality-for-E-and-M-Changes-in-CY-2020MPFS-Proposed-Rule. Accessed January 14, 2019

8. Ganguli I, Shi Z, Orav EJ, et al. Declining use of primary care among commercially insured adults in the United States, 2008-2016. Ann Intern Med 2020;172:240-47 CrossRef Medline

9. Soares GM. The value of clinical interventional radiology. J Am Coll Radiology 2011;8:318-24 CrossRef Medline 